\title{
Integrating hand-off communication into undergraduate nursing clinical courses
}

\author{
Angela Gore ${ }^{1}$, Angela Renee Leasure ${ }^{* 1,2}$, Cathrin Carithers ${ }^{3}$, Barbara Miller ${ }^{2}$ \\ ${ }^{1}$ Department of Veterans Affairs VA Medical Center, Oklahoma City, Oklahoma, United States \\ ${ }^{2}$ College of Nursing, University of Oklahoma Health Sciences Center, Oklahoma City, Oklahoma, United States \\ ${ }^{3}$ College of Nursing, University of Arkansas for Medical Sciences, Little Rock, Arkansas, United States
}

Received: November 24, 2014

DOI: $10.5430 /$ jnep.v5n4p70
Accepted: January 20, 2015 Online Published: January 28, 2015

URL: http://dx.doi.org/10.5430/jnep.v5n4p70

\begin{abstract}
With the growing complexity of healthcare, the ability to communicate becomes essential within the interprofessional team. Healthcare organizations have great expectations for new graduate nurses to communicate skillfully while promoting safe patient care. Nursing students may lack experience with interprofessional communication skills and are fearful of making mistakes which may jeopardize patient safety and undermine student self-confidence. Hand-off is the communication of information between people or disciplines. A student hand-off communication activity was developed and implemented as a clinical skillbuilding activity across several undergraduate clinical nursing courses. Evaluation of this activity revealed positive perceptions from both students and staff.
\end{abstract}

Key Words: Hand-off communication, Nursing education, Nursing student

\section{Introduction}

In today's health care system, the process of information delivery involves numerous health care providers, faculty, and students with varying levels of educational training. To transfer or relay effective hand-off communication requires competence and proficiency. Nursing students may not be able to adequately apply concepts learned within the classroom into nursing practice. ${ }^{[1]}$ The Institute of Medicine (IOM) identified competencies to ensure safety within the healthcare environment and is the foundation for instruction within most nursing programs. ${ }^{[2,3]}$ Academic programs should incorporate these competencies into applicable guides for students. The Quality and Safety Education for Nurses (QSEN) project and the National Advisory Board have developed guidelines to achieve quality and safety competencies within academic nursing programs. These guidelines outline knowledge, skills and attitudes for each competency. ${ }^{[4]}$ Communication becomes the basis of all competent and safe care. Failure to educate the next generation of nurses in effective communication skills will compromise the quality of safe patient care. Hand-off is the communication of information between people or disciplines. Effective hand-off communication among health care providers will have national impact involving all who seek health care services.

The purpose of this project was to implement a process for enhancing effective hand-off communication for novice nursing students as they progress through the clinical environment and transition into safe practicing professional nurses.

\section{Background}

Medical errors would rank fifth on the list of the National Center for Health Statistics in the top ten causes of death in the United States over diabetes, AIDS, breast cancer, accidents, gunshot wounds and Alzheimer's disease if medical errors appeared on the list. ${ }^{[5]}$ Ineffective hand-off communication has been linked to an estimated $80 \%$ of medical

\footnotetext{
${ }^{*}$ Correspondence: Angela Renee Leasure; Email: renee-leasure@ ouhsc.edu; Address: College of Nursing, University of Oklahoma Health Sciences Center, Oklahoma City, United States.
} 
errors in the United States as a leading factor in sentinel events. ${ }^{[5]}$ Hand-off communication that is ineffective can also lead to inappropriate, unnecessary or delayed treatment which may ultimately increase length of hospital stay. ${ }^{[4]}$ St. Joseph Medical Center in Bloomington, Illinois conducted a root cause analysis of sentinel events and noted that communication was a contributing factor in $90 \%$ of the sentinel events. ${ }^{[6]}$ In 2006, the Joint Commission National Patient Safety Goals included a requirement that hospitals implement a standardized approach to hand-off communication, including an opportunity for individuals to ask and respond to questions during the hand-off process. ${ }^{[7]}$

In efforts to reduce medical error, organizations have redesigned processes to standardize hand-off communication between members of the healthcare team. A variety of mnemonics have been developed that outline the process (see Table 1). ${ }^{[8,9]}$ These prompts provide content communication cues to further illustrate and reinforce elements of standardized communication. Different facilities and practices may utilize one or more of these mnemonics to organize and perform end-of- shift hand-off reports between team members. As a result, student hand-off communication tools (SHOC) are individualized to the practice setting. The novice must organize the information they receive and be able to expand and relay the data efficiently and effectively. The use of a structured, standardized hand -off tool helps to ensure that orderly thought is transmitted in a concise and thorough manner to uphold patient safety. Although there are many forms of hand-off communication, this activity focused on the end-of-shift report, a time in which the transfer of information between the oncoming and outgoing nurse occurred.

Nurse educators are challenged to create innovative strategies and techniques to educate nursing students in gathering and transferring pertinent patient health information between members of the health care team effectively and efficiently without event. Although nurse educators broadly believe competencies of quality patient care are addressed in their nursing curricula, evidence indicates current instruction does not meet many objectives that promote safe patient care. ${ }^{[1]}$

Nursing students should be prepared for and learn the process of effective communication that promotes patient safety. ${ }^{[10]}$ The knowledge and skill to carry out a hand-off report may be briefly addressed in the classroom or simulation laboratory setting but is mastered from the observation of mentors and peers; first as students and later as nursing staff. ${ }^{[11]}$ To endorse a culture of patient safety, the integration of a hand-off communication tool called "SHOC" has been introduced into an undergraduate nursing clinical course with the purpose to improve, enhance and standardize effective hand-off communication for nursing students.

Teamwork and collaborative interprofessional communication are essential elements of the transfer of crucial patient

Published by Sciedu Press information. Use of mnemonics such as SBAR (Situation, Background, Assessment, Recommendation) promotes consistency when transferring vital information from one person to another. ${ }^{[12,13]}$ Aids such as SBAR and I Pass the Baton have been used as a teaching strategy during clinical post-conference with nursing students to develop confidence when providing an organized, sequenced hand-off communication. ${ }^{[10]}$ When used in a two-day simulation, nursing students demonstrated improved communication. ${ }^{[14]}$ Such skill building activities can better prepare nursing graduates for the transition into the workforce. When compared to didactic instruction alone, senior nursing students who participated in an intervention which included didactic and role playing demonstrated significantly higher performance scores. ${ }^{[15]}$ This project provided a framework for organizing information to enhance nursing students' proficiency in end-of-shift hand-off communication.

\section{The four functions of hand-off report}

A needs assessment was conducted with the evaluation of simulated case studies that students were required to receive and present an effective hand-off report. Documentation and verbalization of a received report from each student displayed incomplete and incorrect information. The nursing students also were unable to provide an organized, complete, and concise sequenced and consistent hand-off report and complained that they were unaware of medical terminology. Questions arose from this simulated exercise from the nursing students that included the lack of knowledge of the definition and necessity of a hand-off report. Some students believed the nurse already knew about the patients thus making a report unnecessary. An overarching concern voiced by several students was insecurity in their role/knowledge as a novice. As one student asked, "How can we communicate information when we cannot interpret nursing language and the many medical terms?" For this reason, the SHOC tool was developed for the novice nursing students as a transition to the plethora of already established hand-off tools that are available. Independent of the chosen tool, the consistent use of the tool is the ingredient to skill building for successful sharing of information.

A hand-off report encompasses four broad functions. The first dimension, patient review and analysis, addresses the narrative of the patient's clinical condition including communication about the family, tests/procedures, and plan of care. The second function of report is to set norms and expectations of unit performance. This function also includes safety activities such as double-checking provider orders, verifying correct IV fluids and reviewing patient assessment parameters. The third function of unit report is as a method of establishing and validating professional credibility. This may include praise for excellence as well as censure for perceived poor performance or decision-making. The fourth function of report is socialization into the profession as well as the unit culture. ${ }^{[16]}$ 
Table 1: Hand-off Mnemonics

(Leonard M Graham S Bonacum D 2004 human factor: the critical importance of effective teamwork and communication in providing safe care)

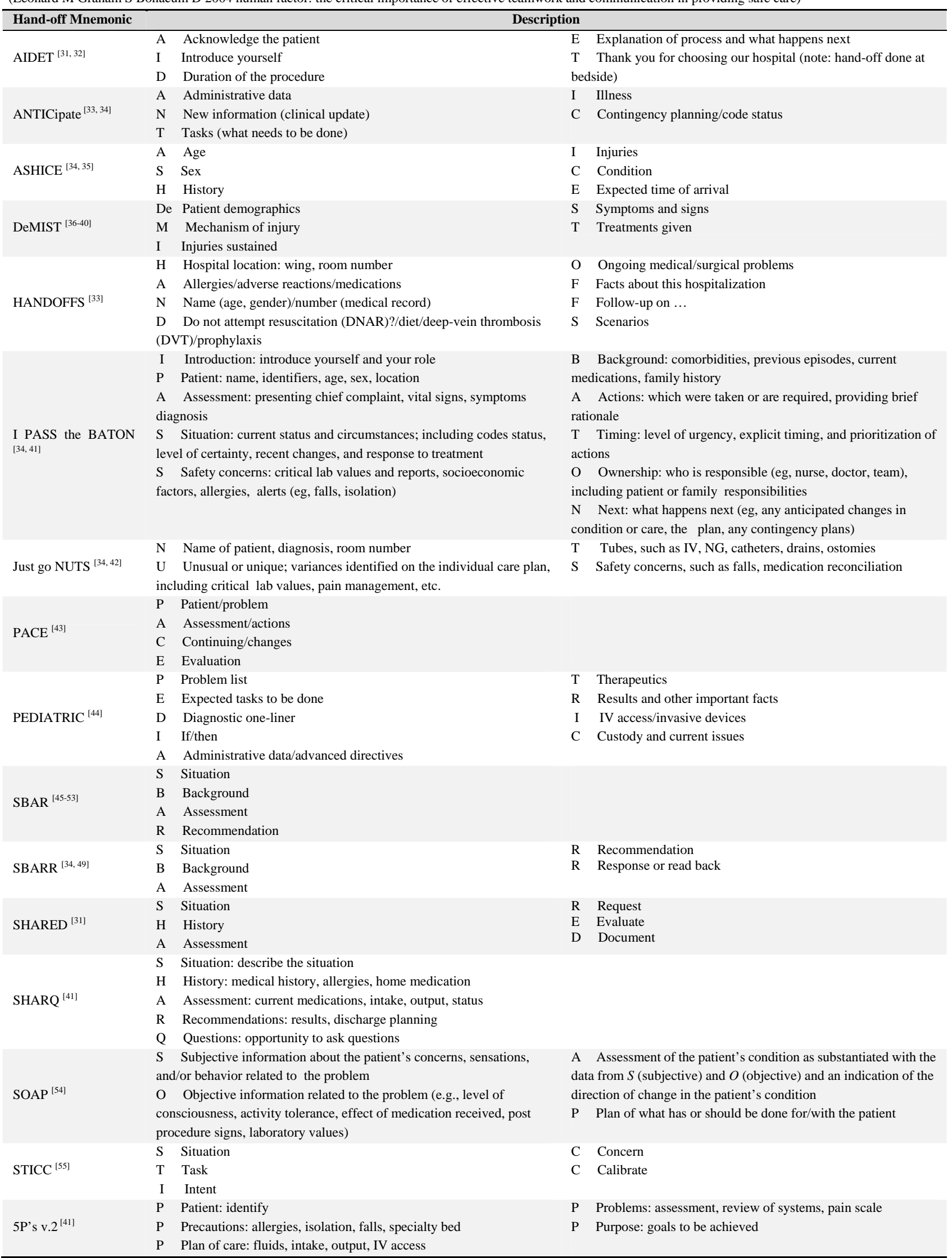




\subsection{Patient review and analysis}

Becoming skilled in hand-off reporting is made easier by providing a written format which the beginning student can use in listening to a report. Listening and documenting aids in cementing the structure of report and provides a venue for later discussion of unclear terms and meanings. Although the process is similar, patient care areas tend to be organized by specialty and as such frequently have unique clinical assessment data as part of their patient review and analysis. The SHOC tool can be modified to meet the needs of the specialty so the student listens for this information during oncoming shift hand-off report and can convey this information as part of the outgoing hand-off communication report between team members.

Using a structured tool facilitates student preparation prior to the delivery of a verbal report and also promotes equality in coverage of multiple patient hand-off reports. Without preparation, the first patient discussed frequently receives the bulk of discussion with subsequent patients receiving decreasing time. Preparation promotes focus and organization to the report and will allow the student to time their hand-off report to enhance efficiency. When giving report on multiple patients, faculty frequently begin by having the student report on one patient with their nurse mentor reporting on the others. Over time the students report on increasing numbers of patients with the final goal of delivery of hand-off report for all of the assigned patients with their nurse mentor observing their report and interjecting information if necessary.

\subsection{Norms and expectations of unit performance}

Faculty serve as culture brokers for nursing students and staff as they work to craft a positive clinical experience for both staff and students. Hand-off is one activity which promotes social cohesion and teambuilding. ${ }^{[17]}$ Units have varying practices and expectations of the structure and content of hand-off reports. For example, some units conduct a central "huddle" before going to the patient bedside for report while others may have a centralized report in a central location such as the nurse's station or break room. At the end of the shift the unit practice for hand-off communication may include the joint review of provider orders and IV fluids for accuracy as a quality and safety measure. Students who rotate through these individual settings for brief periods of time may not be aware of unit safety practices and nuances of the setting. Unit practices and expectations for hand-off activities can be added to the SHOC tool to cue the students for such practices. This builds confidence in the students as they are better able to anticipate and prepare for staff expectations.

During report, students may also witness staff communication regarding performance expectations. Staff may hear a clinical leader convey expectations regarding quality mea- sures or patient expectations. This may be a time when colleagues are censored for not getting the patient out of bed the previous shift or not drawing ordered laboratory tests the prior shift as well as praise for exemplary performance. These conversations convey information about unit expectations but also provide feedback regarding professional expectations and communication.

\subsection{A method of establishing and validating profes- sional credibility}

Hand-off language includes a mixture of medical and nursing abbreviations as well as unit and institution specific jargon. Understanding the vernacular of nursing jargon can be a complex process. For example, a student shared hearing that a patient's "bun" was elevated. Many novice students hearing "bun", associate this word with a hamburger or hot dog bun. Thinking hamburger or hot dog bun is natural as the association with a serum laboratory value is not second nature for many students. Rather this is a complex translation of meanings from "bun" to "B-U'N" and finally to "blood urea nitrogen" level. This process can be compared to the individual seeking to master a secondary language. The individual hears the words in the "foreign" or secondary language and translates them to the native or primary language where a meaning is assigned. Responses are formulated in the native language and then translated into secondary language to be communicated verbally. With practice and skill this process occurs more quickly. Ultimately, as individuals master the secondary language they do not have to translate the words into the primary language to identify the associated meaning. Adding to the challenge, medical jargon is both institution and specialty specific and may include terms such as "sonameter" (centimeter), "Swan" (pulmonary artery catheter), or "DOC'd" (a patient from the prison system).

As students master the jargon their confidence in their ability rises. Credibility is also enhanced when students are able to provide a comprehensive, concise hand-off report which is positively received by the oncoming nurse.

\subsection{Professional socialization and role-taking}

Professional socialization begins with students' first clinical rotation. Anxiety and uncertainty are feelings expressed by new student nurses who want to be seen as worthy of acceptance into the profession. Tools which are adapted to students' clinical level increase comfort and self-confidence. Thus the complexity of the SHOC tool varies by student level of expertise, from novice to advanced beginner. ${ }^{[18-20]}$ Depth and specificity of the hand-off report increases as the student's knowledge and skillset increases throughout the curriculum. Hand-off report is one of nursing's "rites of passage" and as such it is important to the students that their reports are viewed as credible.

Report may also serve as a period of debriefing when nurses 
discuss a patient emergency or complex situation on the unit. This provides an opportunity to build unit cohesion through collaboration and interpersonal support as well as an opportunity to review successful and unsuccessful elements of the situation.

\section{Novice to advanced beginner}

As students begin their nursing education as novice clinicians, they have yet to form a perspective. Habits of thought and action form through academic and experiential learning. ${ }^{[21,22]}$

The clinical setting can be very stressful for the novice student as they embrace the fear of making a mistake with the enthusiasm for beginning the practice of nursing. While the medical record "paints a picture of the patient," handoff communication is couched in the vernacular of "bulletpoints" or "headlines" with a somewhat standardized approach across units and settings. Although there are unitspecific nuances, hand-off communication typically integrates patient background information, social and physical assessment data; provider orders/tests; ongoing plan of care; as well as potential complications. Providing students with a standardized format for use reduces stress and promote an environment for learning and skill building.

As novices, students will provide only the information requested. However, as their theoretical and practical knowledge increases, the hand-off report demonstrates increased specificity and depth. ${ }^{[23]}$ Guided by the Dreyfus Model of Skill Acquisition "24] "the instruction process begins with the clinical instructor's deconstructing the task environment into context-free features the beginner can recognize without the benefit of experience" (p.7). Students utilize the SHOC tool to organize and record the information at the end of each clinical day. Repetition and reinforcement enhances depth and specificity of hand-off reporting.

As students transition to the advanced beginner stage of learning their hand-off communication evolves to include information not specified on the report form; information the student deems to be important. These students tend to describe the clinical situation from how it has impacted themselves rather than the situation or patient. While at first this "student-centered" rather than "patient-centered" perspective can be disconcerting, it is a typical characteristic of an advanced beginner. ${ }^{[19]}$ It is recognized that as students' expertise increases their perspective will evolve to patient-centeredness. ${ }^{[25,26]}$ As habits of thought are cemented through repeated experiences, students rely less on the written SHOC form for report and are able to recall and organize the information by memory.

The use of a structured hand-off communication tool continues to be utilized in a variety of nursing student clinical rotations. As they advance to their final clinical rotation, stu- dents are asked to develop their own written hand-off tool for use at the beginning of the rotation. If the unit has an established hand-off guide this forms the basis of SHOC. Students frequently add information on their SHOC tool to include cues for important patient information and elements of the report to be included such as medication reconciliation following report or patient introductions. Practices vary across facilities and specialties. Early attention to the identification and practice rituals promote role-socialization. Students may refer to earlier tools they have used, tools used on their unit, or tools they have found on the Internet. By the end of the clinical rotation, students may give report verbally without using a written tool if this is the unit practice. However, in the majority of situations, the student and their mentor continue to utilize a structured written tool in lieu of notes jotted on a scrap of paper, paper towel or memory recall. As students progress across clinical courses and become more proficient with SHOC they may expand hand-off communication learning opportunities to giving or receiving report for a patient being transferred into or out of a unit, receiving a patient report from the operating room, or report from the EMS service for an incoming patient. These handoff communication variations are different and opportunities for students to practice with the safety net of a preceptor and faculty is valuable. This does not indicate the students have mastered this task prior to graduation; however, through increased knowledge and repetition, the goal is to provide a smooth transition from the academic to the new professional nurse role.

\section{Learning outcomes}

The structured format of the SHOC facilitated the delivery of information in a sequenced format. An 11 question Likert-type survey was collected from staff mentors and junior year BSN students at the end of each semester over a two semester time period. Quantitative results and thematic analysis of free text comments collected indicated the use of a structured hand-off approach was beneficial in increasing the quality and completeness of student shift hand-off communication. Student responses to the use of a structured hand-off communication tool were very positive. The SHOC tool was particularly appreciated by those students who had utilized a more "trial-and-error" approach in prior clinical rotations.

The authentic positive feedback received by students from staff mentors frequently translates to positive perceptions of both the facility and the nursing specialty (medical-surgical, critical care, OB-GYN, orthopedics etc.) of their unit mentors. The nursing staff acknowledged the differences in knowledge, perceptions and decisions that emerged when interacting with nursing students as a result of SHOC skill building. The SHOC tool provides a means for the nursing staff and nursing students to work together in the clinical setting allowing a feeling of connectedness. 
Through their nursing student mentorship program, one facility extended this project by offering SBAR communication training to the nursing students employed by the facility as part of their recruitment program. In this simulated experience students telephoned a resident to report a patient situation. While the SHOC tool was geared toward end-of-shift hand-off communication between nurses, this exercise focused on interprofessional communication. Students benefit from collaborative learning opportunities prior to gradation. Enhanced knowledge and opportunities for application and practice lessens the learning curve some students experience when transitioning from the nursing student to the registered nurse role.

\section{Conclusion}

The literature provides a clear understanding of how ineffective hand-off communication can have detrimental and lasting effects on patient outcomes. ${ }^{[27-29]}$ As a result of the implementation of the SHOC tool, at the end of the first year of clinical rotations the nursing students had a better grasp of the background and rationale for an effective hand-off report. As a result, students began to recognize pertinent critical health information that needed to be communicated to their nurse mentor in a standardized manner. Nursing students also conveyed feelings of confidence and empowerment in the performance of hand-off communication reports. ${ }^{[30]}$ At the end of their program, nursing students who participated in these learning activities were able to provide a complete, clear, concise and effective hand-off communication to members of the healthcare team.

\section{Conflicts of Interest Disclosure}

The authors declare that there is no conflict of interest statement.

\section{References}

[1] Girdley D, Johnsen C, Kwekkeboom K. Facilitating a culture of safety and patient-centered care through use of a clinical assessment tool in undergraduate nursing education. J Nurs Educ. 2009 Dec; 48(12): 702-5. http://dx.doi.org/10.3928/01484834-200 91113-05.

[2] Medicine IOM. The future of nursing: Leading change, advancing health. Washington, DC: The National Academic Press; 2011.

[3] Committee on Quality of Health Care in America IOM. To Err Is Human: Building a Safer Health System. Washington, DC: National Academic Press; 1999.

[4] Cronenwett L, Sherwood G, Barnsteiner J, Disch J, Johnson J, Mitchell P, et al. Quality and Safety Education for Nurses. Nurs Outlook. 2007 May-Jun; 55(3): 122-31. PMid:17524799 http: $/ / \mathrm{dx}$.doi.org/10.1016/j.outlook.2007.02.006

[5] The Joint Commission. Joint commission center for transforming healthcare tackles miscommunication among caregivers. The Joint Commission; 2010. Available from: http://www. centerfortransforminghealthcare.org/ne ws/display $\cdot$ aspx?newsid=23

[6] Haig KM, Sutton S, Whittington J. SBAR: a shared mental model for improving communication between clinicians. Jt Comm J Qual Patient Saf. 2006; 32(3): 167-75. PMid:16617948

[7] The Joint Commission. Joint Commission National Patient Safety Goals, 2006. Available from: http://www.jointcommission. org/standards_information/npsgs.aspx2006

[8] Vardaman JM, Cornell P, Gondo MB, Amis JM, Townsend-Gervis $\mathrm{M}$, Thetford C. Beyond communication: the role of standardized protocols in a changing health care environment. Health Care Manage Rev. 2012; 37(1): 88-97. http://dx.doi.org/10.1097/HMR .0b013e31821fa503.

[9] Rosenstein AH, O'Daniel M. A survey of the impact of disruptive behaviors and communication defects on patient safety. Jt Comm J Qual Patient Saf. 2008; 34(8): 464-71. PMid: 18714748

[10] Ascano-Martin F. Shift report and SBAR: strategies for clinical postconference. Nurse Educ. 2008; 33(5): 190-1. http://dx. doi.org /10.1097/01. NNE.0000334779.90395.67.

[11] Scovell S. Role of the nurse-to-nurse handover in patient care. Nurs Stand. 2010; 24(20): 35-9. PMid:20191743 http://dx.doi.org $/ 10.7748 / \mathrm{ns} 2010.01 \cdot 24 \cdot 20.35 . \mathrm{c} 7453$

Published by Sciedu Press
[12] Pope BB, Rodzen L, Spross G. Raising the SBAR: how better communication improves patient outcomes. Nursing. 2008; 38(3): 413. http://dx. doi.org/10.1097/01. NURSE. 0000312625.744 34. e8.

[13] Christie P, Robinson H. Using a communication framework at handover to boost patient outcomes. Nurs Times. 2009; 105(47): 13-5. PMid:20063616

[14] Thomas CM, Bertram E, Johnson D. The SBAR communication technique: teaching nursing students professional communication skills. Nurse Educ. 2009; 34(4): 176-80. http://dx.doi.org/1 $0.1097 / \mathrm{NNE} .0 \mathrm{~b} 013 \mathrm{e} 3181 \mathrm{aaba} 54$.

[15] Kesten KS. Role-play using SBAR technique to improve observed communication skills in senior nursing students. J Nurs Educ. 2011; 50(2): 79-87. http://dx.doi.org/10.3928/01484834-20101 230-02.

[16] Streeter ACR. What nurses say: Communication behaviors associated with the competent nursing handoff. Kentucky: University of Kentucky; 2010. Available from: http:uknowledge.uky.edu/g radschool_diss $/ 66$

[17] Kitson AL, Athlin AM, Elliott J, Cant ML. What's my line? A narrative review and synthesis of the literature on Registered Nurses' communication behaviors between shifts. Journal of Advanced Nursing. 2013; 70(6): 1228-42. PMid:24329886 http: $/ / \mathrm{dx}$.doi.org/10.1111/jan.12321

[18] Benner P, Stannard D, Hooper PL. A “thinking-in-action" approach to teaching clinical judgment: a classroom innovation for acute care advanced practice nurses. Adv Pract Nurs Q. 1996; 1(4): 70-7. PMid:9447047

[19] Benner P, Tanner C, Chesla C. From beginner to expert: gaining a differentiated clinical world in critical care nursing. ANS Adv Nurs Sci. 1992; 14(3): 13-28. http://dx.doi.org/10.1097/00012 272-199203000-00005

[20] Benner P, Wrubel J. Skilled clinical knowledge: the value of perceptual awareness, part 1. J Nurs Adm. 1982; 12(5): 114. PMid:6924956 http://dx.doi.org/10.1097/00005110-1 98205000-00003

[21] Benner P, Tanner C. Clinical judgment: how expert nurses use intuition. Am. 1987;87(1):23-31. PMid: 3642979.

[22] Benner P. Designing formal classification systems to better articulate knowledge, skills, and meanings in nursing practice. Am J Crit Care. 2004; 13(5): 426-30. PMid:15470860 
[23] Benner P, Wrubel J. Skilled clinical knowledge: the value of perceptual awareness. Nurse Educ. 1982; 7(3): 11-7. PMid:6918827 http://dx.doi.org/10.1097/00006223-198205000-00003

[24] Dreyfus S, Dreyfus H. A five-stage model of the mental activities involved in directed skill acquisition. Berkeley: University of California, 1980 .

[25] Benner P. Using the Dreyfus Model of Skill Acqisition to describe and interpret skill acquisition and clinical judgment in nursing practice and education. Bulletin of Science Technology \& Society. 2004; 24(188): 188-99. http://dx.doi.org/10.1177/02704676042 65061

[26] Pena A. The Dreyfus model of clinical problem-solving skills acquisition: a critical perspective. Medical Education Online. 2010. PMid:20563279

[27] Beckett CD, Kipnis G. Collaborative communication: integrating SBAR to improve quality/patient safety outcomes. J Healthc Qual. 2009; 31(5): 19-28. PMid:19813557 http://dx.doi.org/10.11 11/j.1945-1474.2009.00043.x

[28] Freitag M, Carroll VS. Handoff communication: using failure modes and effects analysis to improve the transition in care process. Qual Manag Health Care. 2011; 20(2): 103-9. http://dx.doi.o rg/10.1097/QMH. Ob013e3182136f58

[29] Miller K, Riley W, Davis S. Identifying key nursing and team behaviours to achieve high reliability. J Nurs Manag. 2009; 17(2): $247-$ 55. http://dx.doi.org/10.1111/j.1365-2834.2009.00978 . $\mathrm{x}$.

[30] Donahue M, Miller M, Smith L, Dykes P, Fitzpatrick JJ. A leadership initiative to improve communication and enhance safety. American Journal of Medical Quality. 2011; 26(3): 206-11. http: //dx.doi.org/10.1177/1062860610387410.

[31] Mathias JM. A SHARED tool strengthens handoffs. OR manager. 2006; 22(4): 15.

[32] Mathias JM. Passing the baton' for smooth handoffs. OR manager. 2006; 22(4): 13.

[33] Vidyarthi AR, Arora V, Schnipper JL, Wall SD, Wachter RM. Managing discontinuity in academic medical centers: strategies for a safe and effective resident sign-out. J Hosp Med. 2006; 1(4): 257-66. PMid:17219508 http://dx.doi.org/10.1002/jhm.103

[34] Riesenberg LA, Leitzsch J, Little BW. Systematic review of handoff mnemonics literature. American Journal of Medical Quality. 2009; 24(3): 196-204. http://dx.doi.org/10.1177/1062860 609332512 .

[35] Budd HR, Almond LM, Porter K. A survey of trauma alert criteria and handover practice in England and Wales. Emergency Medicine Journal. 2007; 24(4): 302-4. PMid:17384393 http://dx.doi.o $\mathrm{rg} / 10.1136 / \mathrm{emj} .2006 .038323$

[36] Greene JAN. EMS and information sharing: Challenges and innovations in getting patient data from the ambulance to the emergency department and back. Annals of Emergency Medicine. 2014; 64(2): A15-A7. http://dx.doi.org/10.1016/j.annemergm ed. 2014.06 .013

[37] Iedema R, Ball C, Daly B, Young J, Green T, Middleton PM, et al. Design and trial of a new ambulance-to-emergency department handover protocol: 'IMIST-AMBO'. BMJ Quality \& Safety. 2012; 21(8): 627-33. PMid:22626739 http://dx.doi.org/10.1136/b mjqs-2011-000766

[38] Jensen SM, Lippert A, Stergaard D. Handover of patients: a topical review of ambulance crew to emergency department handover. Acta Anaesthesiologica Scandinavica. 2013; 57(8): 964-70. PMid:23639134 http://dx.doi.org/10.1111/aas.12125

[39] Johnson M, Jefferies D, Nicholls D. Exploring the structure and organization of information within nursing clinical handovers. Int $\mathbf{J}$
Nurs Pract. 2012; 18(5): 462-70. PMid:23009375 http://dx.doi .org/10.1111/j.1440-172X.2012.02059.x

[40] Talbot R, Bleetman A. Retention of information by emergency department staff at ambulance handover: do standardised approaches work? Emergency Medicine Journal. 2007; 24(8): 53942. PMid:17652672 http://dx.doi.org/10.1136/emj. 2006. 045906

[41] Sandlin D. Improving patient safety by implementing a standardized and consistent approach to hand-Off Communication. Journal of Perianesthesia Nursing. 2007; 22(4): 289-92. http://dx.doi . org/10.1016/j . jopan. 2007.05.010.

[42] Pass the baton or NUTS for safer handoff. Healthcare Risk Management. 2007; 29: 115-7.

[43] Schroeder SJ. Picking up the PACE: A new template for shift report. Nursing. 2006; 36(10): 22-3. http://dx.doi.org/10.1097/001 52193-200610000-00016

[44] Arora V, Johnson J. A model for building a standardized hand-off protocol. Joint Commission Journal on Quality and Patient Safety / Joint Commission Resources. 2006; 32(11): 646-55.

[45] Andreoli A, Fancott C, Velji K, Baker GR, Solway S, Aimone E, et al. Using SBAR to communicate falls risk and management in interprofessional rehabilitation teams. Healthcare Quarterly. 2010;13 Spec No: 94-101. PMid:20959737

[46] Anonymous. SBAR initiative to improve staff communication. Healthcare Benchmarks \& Quality Improvement. 2005; 12(4): 40-1. PMid:15915702

[47] Ascano-Martin F. Shift report and SBAR: strategies for clinical postconference. Nurse Educ. 2008; 33(5): 190-1. PMid:18769315 ht tp://dx.doi.org/10.1097/01.NNE.0000334779.90395.67

[48] Boaro N, Fancott C, Baker R, Velji K, Andreoli A. Using SBAR to improve communication in interprofessional rehabilitation teams. $\mathrm{J}$ Interprof Care. 2010; 24(1): 111-4. PMid:19370445 http://dx.d oi.org/10.3109/13561820902881601

[49] Guise JM, Lowe NK. Do you speak SBAR? JOGNN - Journal of Obstetric, Gynecologic, \& Neonatal Nursing. 2006; 35(3): 313-4. PMid:16700679 http://dx.doi.org/10.1111/j.1552-6909. 2006.00043.x

[50] Haig KM, Sutton S, Whittington J. SBAR: a shared mental model for improving communication between clinicians. Jt Comm J Qual Patient Saf. 2006; 32(3): 167-75. PMid:16617948

[51] Pope BB, Rodzen L, Spross G. Raising the SBAR: how better communication improves patient outcomes. Nursing. 2008; 38(3): 41-3. PMid:18418180 http://dx.doi.org/10.1097/01.NURS E. 0000312625.74434. e8

[52] Powell SK. SBAR-it's not just another communication tool. Professional Case Management. 2007; 12(4): 195-6. PMid:17667779 http://dx.doi.org/10.1097/01.PCAMA.0000282903.676 $72 . \mathrm{fa}$

[53] Thomas CM, Bertram E, Johnson D. The SBAR communication technique: teaching nursing students professional communication skills. Nurse Educ. 2009; 34(4): 176-80. PMid:19574858 http: //dx.doi.org/10.1097/NNE.0b013e3181aaba54

[54] Kilpack V, Dobson-Brassard S. Intershift report: oral communication using the nursing process. Journal of Neuroscience Nursing. 1987; 19(5): 266-70. http://dx.doi.org/10.1097/0137651 7-198710000-00009

[55] Sutcliffe KM, Lewton E, Rosenthal MM. Communication failures: an insidious contributor to medical mishaps. Academic Medicine. 2004; 79(2): 186-94. http://dx.doi.org/10.1097/0000188 8-200402000-00019 